\title{
Escola organizada em ciclos: as representações sociais de professores considerados bem-sucedidos*
}

\author{
Laêda Bezerra Machado a \\ Jaqueline Andréa Lira Cordeiro Santos ${ }^{b}$
}

\section{Resumo}

$\mathrm{O}$ artigo identifica as representações sociais de ciclos de aprendizagem de professores considerados de sucesso, tendo como referencial a Teoria das Representações Sociais na vertente original de S. Moscovici. A pesquisa foi desenvolvida com 20 professores da Rede Municipal de Recife-PE. Os profissionais responderam a uma entrevista em profundidade. Os depoimentos foram processados pelo software Alceste. O corpus foi organizado em quatro classes denominadas: conhecimentos relacionados à proposta de ciclos; desafios e lacunas da proposta; fatores que promovem o sucesso escolar e os ciclos na prática cotidiana. No conjunto, as classes revelam que os professores conhecem o regime ciclos ressaltando os limites e dificuldades que interferem na sua efetivação. Os resultados deixaram entrever que os professores de sucesso, devido ao compromisso e responsabilidade com que encaram a docência, possuem representações sociais positivas quanto ao potencial transformador da escola, independentemente do seu modo de organização, e são essas representações que orientam suas práticas na escola organizada em ciclos.

Palavras-chave: Representações sociais. Práticas de sucesso. Ciclos de aprendizagem.

\footnotetext{
a Universidade Federal de Pernambuco - UFPE, Departamento de Administração Escolar e Planejamento Educacional e Programa de Pós-graduação em Educação - Núcleo de Formação de Professores e Prática Pedagógica de Recife. Recife, Pernambuco, Brasil.

b Universidade Federal de Pernambuco - UFPE, Departamento de Administração Escolar e Planejamento Educacional e Programa de Pós-graduação em Educação - Núcleo de Formação de Professores e Prática Pedagógica de Recife. Recife, Pernambuco, Brasil. Programa Institucional de Bolsas de Iniciação Científica (PIBIC/CNPq). Pernambuco, Brasil.
}

* Agência financiadora: CNPq. 


\section{Introdução}

No Brasil, desde meados do século XX, o discurso contrário ao fracasso e exclusão escolar foi combatido pelas políticas educacionais. Para garantir uma escola mais democrática, foram tomadas medidas de reestruturação de ensino que possibilitassem não apenas o acesso, mas a permanência e aprendizagem das crianças na escola. Na esteira do debate em torno da democratização da escola, o regime de seriado recebeu várias críticas e, como alternativa a esse modelo, foram formatadas novas sugestões e propostas.

O regime da seriação é um modelo fundamentado em segmentos fixos, denominados séries. Em cada série, o aluno deve aprender um bloco de conteúdos e o não domínio dos conteúdos e das habilidades exigidas para aquele segmento temporal implica em retenção ou reprovação. Conforme pontua Miranda (2005, p. 3) na "série, fixada arbitrariamente como anual, são agrupados os alunos que já sabem e os que ainda não sabem determinados conteúdos. Os que não logram aprendizagem são retidos".

O quadro de exclusão escolar, intensificado pela predominância do regime seriado, deu lugar a diferentes propostas de flexibilização. Essas iniciativas se estruturaram em torno da redefinição dos tempos e espaços escolares, considerando os ciclos de vida, desenvolvimento/aprendizagem dos educandos. O que denominamos ciclos de aprendizagem, nos diferentes locais onde se implantaram, receberam outras denominações, tais como: ciclos de formação, progressão continuada, bloco inicial de alfabetização e ciclos do ensino fundamental (MAINARDES, 2009).

Os ciclos de aprendizagem constituem uma alternativa de organização escolar para garantir a aprendizagem de grupos diversificados. Propõem rupturas menos radicais no currículo escolar, na metodologia e na avaliação, sendo a retenção permitida ao final de cada ciclo. Constituem-se como inovadores, pois buscam modificar os tempos e os espaços da escola, procuram respeitar a diversidade, dão maior atenção à criança, aos adolescentes, aos ritmos de suas aprendizagens e de desenvolvimento.

Em 2001, o município do Recife, apoiado na atual Lei de Diretrizes e Bases da Educação n ${ }^{\circ}$ 9.394/96 (BRASIL, 1996), implantou os ciclos de aprendizagem como regime de organização escolar, o que resultou em interferências na estrutura e funcionamento das unidades escolares. Segundo o documento elaborado pela Secretaria de Educação do Recife (SME), o regime visa assegurar aos estudantes continuidade dos estudos e um tratamento pedagógico mais adequado às suas necessidades de aprendizagem, objetivando o sucesso escolar (RECIFE, 2002). 
Com a implantação do sistema, o ensino fundamental ficou organizado em quatro ciclos, o primeiro com duração de três anos e os três ciclos subsequentes com duração de dois anos cada um. Conforme a legislação municipal, somente é permitida a retenção dos alunos ao final de cada ciclo (RECIFE, 2002).

De modo geral, investigações realizadas por Machado $(2007,2013)$ e Machado e Aniceto (2011) apontaram para uma representação social negativa ou ambivalente dos ciclos de aprendizagem entre professores e gestores de escolas municipais. Os achados dessas pesquisas sugeriram a necessidade de se intensificar os estudos sobre o tema de modo a focalizar as práticas de sucesso nos ciclos de aprendizagem. Dito de outra forma, se as representações sociais são tão negativas, o que explicaria as práticas de sucesso na escola municipal? Com tal perspectiva, este artigo, resultado de uma pesquisa mais ampla, procura explicitar as representações sociais de ciclos de aprendizagem construídas por professores bem-sucedidos, mostrando o que há de mais objetivado e ancorado nessas representações.

\subsection{Práticas de sucesso escolar}

A revisão de literatura sobre prática docente de sucesso indica a complexidade da temática. Rios (2002) afirma que o professor bem-sucedido é competente e tem sua competência manifestada através de quatro dimensões: ética, política, técnica e estética. A dimensão técnica está relacionada ao domínio de saberes e habilidades no campo de atuação; a dimensão política sugere uma visão crítica das ações e do compromisso do professor com as necessidades da sociedade; a dimensão ética constitui um elemento de mediação entre as dimensões técnica e a política, garantindo, assim, uma reflexão crítica sobre os valores comuns à prática do indivíduo em sociedade. Por fim, a dimensão estética vincula-se ao olhar sensível do profissional para com o seu fazer docente.

Na literatura especializada, em geral, (ANDRADE; RAITZ, 2012; BUENO; GARCIA, 1996; MACHADO; AZEVEDO; FREIRE, 2013; MARIANO; DINIZ; TANCREDI, 2007; MENDES, 2008; MONTEIRO, 2011), o tema práticas bem-sucedidas remete a pesquisas qualitativas do tipo estudo de caso, que tiveram como sujeitos o professor de ensino superior e do ensino fundamental, com destaque para os alfabetizadores. As investigações sobre o assunto abordam as boas práticas de modo variado, enfatizando a definição do bom professor, importância da prática docente para superação do fracasso escolar e a influência da trajetória da formação profissional para uma prática de sucesso. A análise da literatura revela que o professor bem-sucedido é um profissional comprometido com seu trabalho, bem como aquele que constrói uma boa relação afetiva com os alunos. Mostra, também, que o reconhecimento do trabalho docente, valorização 
profissional, apoio da comunidade escolar e de pais de alunos concorrem para a efetivação de práticas de sucesso.

Este artigo, ao abordar professores de sucesso, ajuda a caracterizar melhor práticas denominadas bem-sucedidas, contribui para valorizar o trabalho docente e reforça o papel das representações na orientação das ações e práticas dos sujeitos.

\subsection{Teoria das Representações Sociais}

Devido à necessidade de explicar o mundo e agir sobre ele, os sujeitos criam representações sociais, que situam os sujeitos nos seus grupos de pertença e contribuem para compreensão dos desafios da realidade. A Teoria das Representações Sociais foi idealizada pelo psicólogo Serge Moscovici, em 1961, que afirma "são teorias, ciências coletivas destinadas à interpretação do real” (1978, p. 47).

Representar, na perspectiva de Moscovici (1978; 2007), é mais que opinar, é agir com base nas explicações que se tem e se faz daquilo que nos cerca. É comportar-se conforme os sentidos atribuídos aos objetos e às situações. A esse respeito, Sá (1998) explica que uma representação social é sempre de alguém e de alguma coisa. Para o autor, não se pode falar nas representações de um sujeito sem especificar os objetos representados, assim como não se pode falar em representação sem deixar claro quem representa. Ao representar, sujeito e objeto se misturam. As representações sociais têm um caráter prático, portanto, elas são o pano de fundo para as ações dos sujeitos.

A abordagem teórica das representações, adotada neste artigo, é a original, ou seja, aquela que dá ênfase aos aspectos socioculturais, concentrando-se na identificação e análise dos processos de formação do fenômeno representado. Essa vertente tem Moscovici e Jodelet como seus principais expoentes.

Moscovici (1978), ao detalhar o processo de construção das representações sociais, afirma que elas emergem de dois processos: objetivação e ancoragem, que concorrem para transformação do não familiar em familiar.

O processo de objetivação refere-se "à operação formadora da imagem, tornando o conhecimento algo palpável, quase tangível para entendê-lo" (MACHADO, 2013, p. 324). É dar nome aos objetos, compará-lo a algo já visto. Ancorar é materializar o conceito, aproximando o estranho às categorias de pensamento já existentes a partir de comparações do novo com "categorias estocadas na memória" (BONA; SILVA, 2009, p. 11). Ancorar é mais que nomear o objeto. "É 
o engendramento, a incorporação definitiva desse novo objeto em nosso sistema de referência" (MACHADO, 2013, p. 324).

A abordagem culturalista das representações assume um caráter processual, ou seja, exige que elas sejam estudadas não apenas como um produto, mas como processo, isto é, implica em, por meio das investigações, buscar a sua gênese e mecanismos de construção. Este artigo investiga as representações sociais de ciclos de aprendizagem, formuladas pelos professores bem-sucedidos nas suas relações com o trabalho docente que desenvolvem.

\section{Metodologia}

Em virtude da adoção do aporte teórico das representações sociais, a abordagem metodológica do trabalho é de natureza qualitativa. Como procedimento de coleta de informações, utilizou-se a entrevista em profundidade que, segundo Duarte (2005), permite explorar e aprofundar os assuntos de interesse para o pesquisador quando investiga um objeto.

$\mathrm{O}$ artigo resulta de pesquisa desenvolvida com docentes de sucesso vinculados a 10 escolas da Rede Municipal do Recife-PE (RME), localizadas em diferentes regiões político-administrativas (RPAs) e que obtiveram as melhores notas no IDEB-2011.

Foram entrevistados 20 professores que lecionavam em diferentes ciclos do ensino fundamental, sendo quatro homens e 16 mulheres. Para a escolha dos participantes foi solicitado aos coordenadores das instituições que indicassem docentes considerados bem-sucedidos em seu trabalho pedagógico na escola. As entrevistas foram individuais, gravadas (com anuência dos participantes) e tiveram duração variada entre 15 minutos e duas horas.

Essas entrevistas foram realizadas nas próprias escolas e, em dois casos, na própria sala de aula, sem interferências das crianças. Durante o contato, percebeu-se que os professores demonstraram preocupação sobre o que se definiu como ser um docente bem-sucedido. A maioria fez questão de dizer que, tendo em vista o salário que recebem e as condições de trabalho nas quais atuam, não se consideravam bem-sucedidos na profissão. Contudo, quando se explicava o sentido que se estava atribuindo a esta expressão, eles se reconheciam como comprometidos e responsáveis. Mesmo assim, insistiam que outros elementos inviabilizavam o trabalho docente. Lembraram, principalmente, os salários, a precarização das escolas e a falta de parceria com as famílias. 
De cada uma das 10 escolas, participaram dois professores, com idades entre 27 e 56 anos. Dos participantes, 15 eram formados em Pedagogia, quatro tinham formação em licenciaturas diversas, um deles apenas o magistério e oito concluíram a especialização. Quinze docentes tinham entre 11 e 30 anos de profissão e cinco tinham menos de 10 anos como professores. Quatro professores lecionavam em turmas de $3^{\circ}$ e $4^{\circ}$ ciclo, três eram professores do $2^{\circ}$ ciclo e 13 eram professores alfabetizadores $\left(1^{\circ}\right.$ ciclo). Essa caracterização revela que foram mais indicados, como bons professores, os alfabetizadores e aqueles docentes com mais de 10 anos de atuação profissional.

Depois de transcritas, as entrevistas foram analisadas com auxílio do software Análise Lexical Contextual (Alceste) ${ }^{1}$. O uso do software em pesquisas que utilizam a Teoria das Representações Sociais é comum. (CAMARGO, 2005; POMBO DE BARROS, 2011).

O Alceste foi introduzido no Brasil em 1998 e possibilita a análise de dados textuais, gerando classes lexicais formadas por Unidades de Contexto Elementar (UCEs). As classes são organizadas, em relatório gerado pelo programa, em forma de dendrograma ${ }^{2}$. Elas são formadas por palavras de contexto similar e estáveis, ou seja, de vocabulário semelhante. O software separa as palavras com base na importância que tiveram durante as entrevistas. Lima e Fernandes (2008) definem as classes como contextos semânticos que guardam características linguísticas semelhantes, isto é, um vocabulário regular que expressa o campo contextual de um objeto.

Por se tratar de uma análise qualitativa dos textos, o Alceste, ao organizar as classes, não prioriza o número de vezes ou frequência (f) que uma palavra foi enunciada, mas sua importância no contexto discursivo. Pode-se verificar que a disposição das palavras nas classes não segue uma ordem. Por exemplo, na classe 1, avaliação não foi uma palavra com frequência altíssima, mas no contexto discursivo das entrevistas (UCE) foi um termo significativo, enfático para a maior parte dos entrevistados, o que justifica sua posição na classe.

Camargo (2005) afirma que as classes podem indicar representações sociais ou campos de imagem ou aspectos de uma representação social.

Para organizar o material, o Alceste procede à leitura do material textual e separa as palavras desse texto, observando suas ocorrências e classificando-as.

\footnotetext{
1 Conforme o software utilizado, classes constituem agrupamentos de palavras de contexto e vocabulário semelhantes.

2 Dendrograma é um tipo específico de diagrama ou representação icónica, alguns denominam de árvore, que organiza as classes resultantes do processamento estatístico do Alceste.
} 
O Programa opera em três fases. Na primeira, faz a leitura do texto, identifica as palavras, calcula o número de ocorrências e constrói o dicionário; na segunda fase, calcula as matrizes de dados e faz a classificação das UCEs. E por fim, faz os cálculos complementares e fornece as unidades de contextos específicas de cada classe, isto é, contextualiza o vocabulário específico de cada uma.

No caso da pesquisa que deu origem a este artigo, cada entrevista correspondeu a uma Unidade de Contexto Inicial (UCI), totalizando o correspondente a 20 UCIs. O software analisou $81 \%$ desse corpus, uma quantidade satisfatória, visto que é aceitável que o programa processe, pelo menos, $70 \%$ do material (LIMA; FERNANDES, 2008).

\section{Resultados e discussão: ciclos de aprendizagem nas representações sociais de professores considerados bem-sucedidos}

Após o processamento, o software Alceste, através da classificação hierárquica descendente, gerou o dendrograma (Quadro), que dividiu o corpus em dois subcorpus, o primeiro deu origem a classe 1 , o segundo resultou nas classes 2,3 , e 4. Todas as classes estão articuladas e foram nomeadas de acordo com o conjunto das palavras contidas em cada uma e seus contextos de verbalização. Respeitando o conteúdo de cada agrupamento, elas foram, respectivamente, denominadas de: Conhecimentos relacionados à proposta de ciclos (Classe 1); Desafios e lacunas da proposta (Classe 2); Fatores que promovem o sucesso escolar (Classe 3) e Ciclos na prática cotidiana (Classe 4). Com as referidas classes, dispostas na Quadro, procurou-se caracterizar as representações que os professores de sucesso construíram dos ciclos de aprendizagem, buscando apreender a teia de sentidos, que envolve o regime de ciclos para esses docentes.

A primeira classe - Conhecimentos relacionados à proposta de ciclos - revela que os professores bem-sucedidos conhecem a proposta de ciclos. Ao usarem termos próprios do documento, proposta da RME, indicaram ter tido acesso a informações sobre os princípios dessa forma de organização escolar. A classe foi composta por 535 UCEs, o correspondente a $65 \%$ do corpus analisado. Seu conteúdo evidencia que muitos elementos da proposta de ciclos de aprendizagem foram ancorados pelos professores e fazem parte de seus esquemas de pensamento e de suas práticas.

Como se vê na Quadro, a primeira classe agrupa as palavras: ciclo ( $\mathrm{f}=269$ ); ano $(\mathrm{f}=288)$; proposta $(\mathrm{f}=113)$; avali (avaliação, avaliando, avalio, avaliar) $(f=68)$; compet (competências, competência, competente) $(f=48)$; processo 
Quadro. Dendrograma referente à Classificação Hierárquica Descendente (CHD) do corpus ciclos e sucesso.

\begin{tabular}{|c|c|c|c|c|c|c|c|}
\hline \multicolumn{2}{|c|}{$\begin{array}{l}\text { Classe } 3 \\
\text { Fatores que promovem } \\
\text { o sucesso escolar }\end{array}$} & \multicolumn{2}{|c|}{$\begin{array}{c}\text { Classe } 4 \\
\text { Ciclos na prática } \\
\text { cotidiana }\end{array}$} & \multicolumn{2}{|c|}{$\begin{array}{c}\text { Classe } 2 \\
\text { Desafios e lacunas } \\
\text { da proposta }\end{array}$} & \multicolumn{2}{|c|}{$\begin{array}{c}\text { Classe } 1 \\
\text { Conhecimentos relacionados } \\
\text { à proposta de ciclos }\end{array}$} \\
\hline Palavras & $f^{1}$ & Palavras & $f$ & Palavras & $f$ & Palavras & $\mathrm{F}$ \\
\hline Sucesso & 33 & Quadro & 14 & Mãe & 21 & Ciclo & 269 \\
\hline Professor & 68 & Aula & 21 & Família & 44 & Ano & 288 \\
\hline Profissão & 12 & Motiv+ & 6 & Tarefa & 14 & Avali+ & 68 \\
\hline Compromisso & 14 & Exijo & 6 & Casa & 18 & Proposta & 113 \\
\hline Acredit+ & 42 & Histor+ & 10 & Bolsa família & 11 & Compet+ & 48 \\
\hline Postura & 10 & Atenção & 4 & Deposito & 8 & Processo & 49 \\
\hline Responsabilidade & 11 & Amor & 4 & Farda & 5 & Caderneta & 21 \\
\hline Valoriz+ & 9 & Alegria & 4 & Lápis & 7 & Acompanh+ & 45 \\
\hline Busct & 19 & Prazer & 5 & Falt+ & 44 & Aluno & 188 \\
\hline
\end{tabular}

f: frequência. Diz respeito ao número de vezes que a palavra apareceu no corpus processado, ou seja, foi verbalizada durante as entrevistas.

Fonte: Elaborada pelas autoras, 2014.

( $\mathrm{f}=49)$; caderneta $(\mathrm{f}=21)$; acompanh (acompanha, acompanhado, acompanham, acompanhamos $)(f=45)$ e aluno $(f=188)$.

As palavras aluno, processo e acompanhamento, mesmo sem terem obtido as frequências mais altas da classe, foram indicadas devido ao forte papel que assumem na proposta curricular da rede. Os professores ressaltaram que os ciclos representam um novo olhar para o processo de aprendizagem, uma nova forma de se relacionar com os alunos e alteração no modo de conceber a aprendizagem dos estudantes. Afirmaram:

[...] eu vejo como uma estrutura de ensino que vai possibilitar o trabalho voltado para o aluno, para construção de determinadas competências, é... Se este aluno não atingir certas competências, ele tem a oportunidade de seguir adiante... É um sistema, é uma organização que o aluno não só tem, por exemplo, um ano para se alfabetizar... (P2)

Na proposta, nós podemos perceber que é dado um tempo maior para que cada aluno possa desenvolver as habilidades

Codificamos os 20 docentes entrevistados com a letra maiúscula (P) significando professor, seguida do número do protocolo de entrevista. 
e competências pertinentes ao nível de ensino em que estão inseridos. Isto é muito bom, pois busca respeitar o tempo de cada um, porque a gente sabe que cada aluno tem seu ritmo, as turmas são heterogêneas, e se a gente pensar que vai pegar uma turma prontinha, acabada com todo mundo no mesmo nivel, estamos vislumbrando uma doce ilusão. (P19)

Eu acredito que a questão, assim... Eu acompanhei aluno, o ciclo ele facilita muito, ele estimula isso, você acompanhar o aluno e ai você vai vendo. (P7)

O professor hoje, ao meu ver, ele mudou a visão... Ele mudou aquela visão que professor é detentor do saber e o aluno só servia para depositar conhecimentos. De certa forma [...] isso mudou... Eu acho que isso contribuiu muito, ver o aluno como um ser em potencial, capaz de aprender, isso mudou... Porque antigamente era só aquele depósito $(\mathrm{P} 3)$

Tais posicionamentos dos entrevistados se relacionam ao conteúdo do documento elaborado pela SME (RECIFE, 2003), no qual aluno e professor são reconhecidos como sujeitos do processo de ensino aprendizagem. Acompanhamento, construção do saber e processo são termos recorrentes na proposta e que foram incorporados aos discursos dos professores. O texto da proposta prescreve: "quando acompanha a construção de seus alunos, o professor tem a oportunidade de refletir sobre sua prática” (RECIFE, 2013, p. 164).

Pode-se admitir que as palavras processo e acompanhamento, mencionadas nos discursos dos professores, indicam mudanças nas formas de conceber e exercer a prática pedagógica, pois as competências aparecem no lugar de notas e a caderneta como instrumento de registro substitui as provas. Os professores referem-se à "caderneta" ou "diário de classe" como indispensável para o processo de avaliação, percebem a importância do registro cursivo e cotidiano das aprendizagens dos alunos. Destacaram os docentes:

[...] eu acho que é positivo esse acompanhamento sistemático que a gente consegue ter, tá certo? Eu acho que é o olhar que a gente também consegue direcionar para o aluno, que a gente vai acompanhando ele e vai vendo principalmente quando a gente olha essa questão de processo... (P16) 
[...] Nosso diário (caderneta) vem um pouquinho dessa versão, é a partir dele que a gente faz o planejamento e esse planejamento a gente faz a avaliação das crianças vendo se as competências foram construídas ou estão em construção. (P12)

[...] é uma proposta que abre um leque de opções pra gente trabalhar, é algo que, com tempo... Para tá olhando, estudando, pra tá amadurecendo... Você vê o processo, desenvolve um trabalho muito bom, acompanhando as crianças. (P11)

Conforme os contextos (UCEs), nos quais essas palavras foram ditas, identificou-se que, embora os docentes acreditem na organização escolar em ciclos, para eles, muito precisa melhorar para a garantia de sua efetivação. Com base nos conhecimentos adquiridos sobre os ciclos de aprendizagem, esses profissionais apontam suas lacunas.

Os entrevistados ressaltam a importância do acompanhamento, porém alegam que o quantitativo de alunos em sala, ausência de apoio pedagógico e falta de suporte ao docente inviabilizavam o êxito da proposta de ciclos. Afirmaram:

Eu tenho muita dificuldade, né, em virtude da quantidade de alunos que temos por turma, em média de 35 a 40 adolescentes, a gente não tem esse espaço pra parar semanalmente como o ciclo sugere... Por exemplo, eu registro aqui que o aluno tem dificuldade na aprendizagem e que precisa no ano seguinte ter um acompanhamento mais sistemático e não tem essa quantidade de profissional disponivel para dar esse suporte que essa criança precisa. $(\mathrm{P} 4)$

A gente tem uma sala com muitos alunos por turma, onde faltam materiais didáticos, os materiais chegam tarde, os livros chegam tarde, a gente tem uma quantidade de xerox pra tirar, é mínima, dá pra fazer uma ou duas atividades por mês, se eu quiser mais tenho que tirar do meu bolso. Falta material, falta jogos, falta livros... (P13)

No que se refere à avaliação, os docentes destacaram que, antes de ser implantado o regime de ciclos, ela era um instrumento de classificação, usado para punir o aluno, porém, com os ciclos, passou a ser um processo de acompanhamento, contínuo e individualizado. Contudo, de acordo com os depoimentos organizados na Classe 
1, os participantes demonstram dificuldades e contradições ao se referirem às práticas avaliativas que desenvolvem. Eis alguns depoimentos:

Eu gosto de trabalhar determinados conteúdos e depois fazer avaliação é uma coisa que a gente não é cobrado nesse sentido, a gente pode avaliar o aluno numa atividade de classe, a gente pode avaliar numa leitura, numa aula assim... Mas, eu gosto de trabalhar o conteúdo e no fim de cada unidade fazer as avaliações, porque eu acho que é mais uma forma, não é a única forma, mas é mais uma forma de avaliar o meu aluno. (P14)

Trabalho muito construindo conhecimento com eles. Sou tradicional porque eu faço prova, embora essas provas não vem para caderneta, então é um instrumento de avaliação para mim, para eu saber se eles avançaram, mas, isso também não prejudica eles em nada, porque não conta como nota, não é atribuído uma nota. É uma avaliação para minha prática e também porque a gente é avaliado constantemente na vida, constantemente somos avaliados em relação a tudo. (P7)

Eu no dia a dia acompanhando a tarefa, acompanhando o interesse deles, nas tarefas que vem de casa [...] Geralmente eu faço ditado para ver como eles estão, entendeu? Eu estou sempre avaliando, quando eu vejo eles crescerem... Eu fico vibrando. (P8)

[...] Muito interessante é você dar um tempo maior para a criança aprender... Veja que coisa, que avanço que a gente tinha... Na minha época era: não aprendeu determinado conteúdo? Fez uma prova ruim? Não foi bem na avaliação? Foi pra final não deu certo? Reprovado. E se foi reprovado não repete aquela matéria ou aquele conteúdo. Repete tudo! Então é uma chance maior, um tempo maior para poder aprender. (P12)

Estudos de Machado (2013), Machado e Aniceto (2010), Naiff e Naiff (2013), Petrenas e Lima (2007) e Sousa (2007) revelam que a forma de avaliação proposta pelos ciclos é referenciada nas representações de diversos profissionais da educação e na própria estrutura da proposta. Embora reconheçam os méritos do regime de ciclos, os profissionais ouvidos, nesses estudos, revelaram dificuldades para lidar com a avaliação formativa. Sousa (2007) destaca que, dentre as práticas e rotinas escolares, a mais "atingida" com os ciclos foi a avaliação, mas insiste que a mudança da prática avaliativa torna-se necessária para a sua efetivação. 
Alguns dos professores de sucesso, ouvidos nesta pesquisa, alegaram que sem reprovação as crianças não aprendem, não estudam. Como elas não ficam mais retidas, o professor perde o seu poder perante os alunos. Comentaram:

[...] Muitos alunos sabem que vão passar e não fazem as atividades, não ficam quietos na sala, não colaboram. Sabem que vão passar, então não fazem muita coisa. Quando eles sabiam que tinham que ter uma nota, que tinham que passar... Eles paravam mais e ficavam mais quietos... A gente tinha mais um dominio sobre eles. (P13)

[...] sobre o ciclo, foi essa questão da retenção, porque se eu não posso reter o menino e mando para o próximo ano, eu só estou aumentando a bola de neve... (P11)

Eu acho que a intenção do é favorecer o aluno, fazer com que o aluno tenha mais tempo e que ele não fique desmotivado pela retenção, $e$ esteja sempre na escola, não desista, é uma forma de estímulo, porém não acho que isso não funciona... Eu acho que é mito negativo essa questão da promoção automática. (P6)

[...] embora goste da proposta não concordo com essa aprovação. Não é passando o menino que vou estar ajudando a ele (aluno). (P20)

Esses depoimentos estão em consonância com a conclusão de Naiff e Naiff (2013, p. 546), pois, segundo os referidos autores, "as práticas pedagógicas conservadoras confundem não reprovar, com não avaliar”. Bona e Silva (2009), também, mostraram que as representações constituem um sistema imunológico, que protege a identidade do sujeito que representa. Historicamente, o professor foi o centro do processo educacional e com a reprovação exercia certo poder sobre o grupo classe, o que lhe conferia uma identidade. Hoje, o processo avaliativo, defendido pela proposta de ciclos, fere essa identidade, mexe com suas representações de ensinar e aprender, o que explica sua resistência a não retenção e as dificuldades em aderir à avaliação formativa.

A avaliação formativa, preconizada pela proposta de ciclos de aprendizagem (2002), não implica em julgamentos sobre a aprendizagem, mas procura valorizar o que o aluno já sabe e os caminhos percorridos para alcançar o conhecimento. Enfatiza o processo de construção do conhecimento, aquilo que o aluno ainda não sabe e o caminho que deve percorrer para "vir a saber", 
o que é potencialmente revelado em seu processo, suas possibilidades de avanços e suas necessidades de superação, sempre transitória, do não saber para o saber (ESTEBAN, 2003).

Na mesma linha de argumentação, Perrenoud (1999) considera o caráter regulatório da avaliação formativa tomada como um processo deliberado e intencional, tendo como objetivo controlar os processos da aprendizagem a fim de desenvolver ou redirecionar essa mesma aprendizagem.

Em seus relatos, os professores fizeram menção às contradições entre a avaliação formativa defendida pela RME e as avaliações institucionais em larga escala exigidas pelo sistema. Segundo eles, é discrepante o município exigir dos professores pareceres avaliativos da aprendizagem, acompanhamento sistemático da construção do conhecimento e, a nível nacional, serem exigidos resultados quantitativos que classificam e excluem.

Além das restrições feitas ao processo avaliativo e promoção dos estudantes, outras dificuldades referentes à efetivação dos ciclos foram ressaltadas pelos docentes bem-sucedidos, nas entrevistas. As inquietações e dificuldades desses profissionais vão desde a falta de formação e apoio pedagógico até aspectos estruturais, como falta de material administrativo e didático, espaços escolares improvisados e número excessivo de alunos em sala de aula. Boa parte deles relembrou, ainda, a forma como a proposta de ciclos foi implantada, reiterando sua imposição à rede. Eis alguns dos comentários feitos pelos professores:

A estrutura física é uma coisa que, de certa forma a gente sente muita dificuldade, se você vê aqui a escola é muito pequena, as salas são bem pequenas mesmo. Não tem um espaço para um recreio. A gente não tem o espaço adequado, a gente improvisa. A gente não tem uma equipe multifuncional, só temos uma itinerante de educação especial, mas é uma só e ela tem que dar conta da escola... A gente não tem uma psicóloga, uma fonoaudióloga... (P7)

Essa proposta em si, da forma como ela tá imposta, ela não tem muito como ajudar... Eu acho que a escola e os professores não tem o que fazer nesse sentido. [...] Quem tá gerindo a educação precisa rever esse modelo. Não tem como o professor fazer milagre com todos os problemas. (P18) 
[...] O professor precisa de estrutura para trabalhar, precisa de condição de trabalho e formação. O sistema tem que dar isso, [...] para que o professor em sala faça seu trabalho com competência. O menino vem sem borracha, sem farda, sem lápis e ninguém quer saber, não tá nem ai!! (P9)

Esse sistema de ciclos ele foi implantado no periodo que comecei na rede do Recife e gerou uma polêmica muito grande. (P3)

Semelhantes críticas e comentários para com os ciclos foram, também, detectados por Machado (2007), Machado e Aniceto (2010) e por Jacomini (2007). Esta última, ao analisar a proposta de ciclos em São Paulo, constatou que os educadores não se apropriaram da lógica de ciclos e representam o sistema como algo imposto e desarticulado da realidade educacional no estado.

Admite-se que, no processo de construção das representações, as ideias são selecionadas pelo sujeito e, nessa seleção, alguns elementos são privilegiados em detrimento de outros. O conteúdo dos depoimentos organizados na Classe 1 revela que muitos elementos da proposta de ciclos foram ancorados pelos professores e fazem parte de seus esquemas de ação. Esses profissionais incorporaram aos seus discursos e práticas uma maior preocupação com o aluno, a defesa do acompanhamento sistemático das aprendizagens e o entendimento de que a educação é um processo. Esse novo olhar, segundo os professores, foi possibilitado pela proposta de ciclos. No entanto, há um estranhamento e certa recusa para com a não retenção e ao funcionamento geral dos ciclos. Os professores representam de forma negativa sua implementação e criticam a falta de apoio recebida por parte da gestão municipal. Consideram-se desorientados em relação a alguns dos processos e desaprovam outros, por exemplo, as condições reais de trabalho no regime de ciclos. Declararam:

[...] A rede ela é muito engessada, você tem que nivelar por baixo. É falta de estrutura, falta de incentivo, má remuneração, enfim... Todos os problemas estruturais atrapalham e comprometem, enfim... (P18)

[...] falta conhecimento da proposta, que ela é imposta, tem que seguir, funciona, mas, são pouco recursos, falta muita coisa pra que funcione $100 \%$. (P5)

Se você analisar a proposta tal qual como foi escrita, você vai perceber um ambiente maravilhoso propício para o desenvolvimento de todos. Porém, essa realidade ficou no papel. [...] Desvantagens, 
temos de monte. Olhe, estou com um $5^{\circ}$ ano, que é o segundo ano do $2^{\circ}$ ciclo. E acredite se puder tenho alunos que não sabem ler, agora eu perguntei a direção da escola no início do ano, o que é que esses alunos estão fazendo no final do segundo ciclo se não sabem ler? Se o ciclo diz que os alunos com dificuldades seriam acompanhados. Ué! Cadê o acompanhamento desse povo? (P19)

Em síntese, o conteúdo da Classe 1 revela que os professores considerados bem-sucedidos da RME objetivaram a proposta de ciclos de aprendizagem, fazem referência aos conceitos, à fundamentação e ao modo como foi construída. Ao mesmo tempo em que constroem esses esquemas figurativos, com seus posicionamentos para com a avaliação, falta de apoio e precárias condições de trabalho nas escolas, ancoram os limites para efetivação do sistema de ciclos.

A Classe 2 - Desafios e lacunas da proposta - organiza elementos relacionados à inquietação dos professores, no que se refere às condições que inviabilizam a efetivação da proposta, enfatizando o relacionamento ou parceria da escola/professor com a família. A classe foi composta por 88 UCEs, número correspondente a $11 \%$ do corpus. Na Classe 2, foram as seguintes palavras: mãe $(\mathrm{f}=21)$; família $(\mathrm{f}=44)$; tarefa $(\mathrm{f}=14)$; casa $(\mathrm{f}=18)$; bolsa família $(\mathrm{f}=11)$; depósito $(\mathrm{f}=8)$; farda $(\mathrm{f}=5)$; lápis $(\mathrm{f}=7)$ e falt (falta, faltam, faltou) $(\mathrm{f}=44)$.

Os desafios e limites foram mencionados nas outras classes, porém, principalmente na Classe 2, foram mais reclamados pelos docentes. Eles destacaram a falta de integração da família, tarefas de casa que não são feitas, crianças que chegam à escola sem farda e/ou material escolar. O conteúdo das falas da Classe 2 indica que lidar com as condições do aluno e suas famílias constitui o desafio, que mais afeta o trabalho do professor na escola em ciclos. Eis alguns trechos de depoimentos dos entrevistados:

[...] Você às vezes se vê no desespero porque não tem quem faça o papel de mãe ou de pai, ou sei lá... De quem possa dar um reforço, orientar, incentivar, estimular... Não tem. São crianças jogadas no mundo e não tem ninguém por elas. [...] Acredito na proposta, mas tem que ter melhoras. Eles aprenderiam mais nos ciclos se a gente tivesse esse suporte. (P5)

[...] a criança não trouxe o lápis, tio eu não trouxe o caderno [...] Não tem nada que me incomode mais do que isso, porque eu, isso reflete na falta de comprometimento de que a família tem. Eu tenho 
muitos alunos que os pais são analfabetos, mas eu acho que isto não impede que eles cheguem em casa e eles cobrem do filho. Poxa! Você leu a tarefa, tem alguma coisa pra fazer hoje? O que foi que você aprendeu hoje na sala? Você se comportou? Deixe eu ver seu caderno. A partir do momento em que os pais se interessam e cobram, eles participam desse processo, as crianças sentem mais interesse de fazerem a parte delas. (P18)

A gente chega sente aquela família que acompanha, o sucesso dos meninos é outro, já aqueles que a família não tá nem aí, às vezes consegue sucesso, porque graças a Deus é muito deles. Uma coisa é quando você tem acompanhamento da família, isso falta... Falta mesmo... (P9)

Conforme o material organizado na Classe 2, pode-se depreender que os docentes fazem uma ligação direta entre alunos que fracassam e famílias ausentes. Ao falarem sobre os bons alunos, ressaltam que são aqueles cujas famílias vão à escola, exigem e dão atenção às crianças. Essa representação é compartilhada pelos participantes.

Na visão dos entrevistados, o Programa Bolsa Família constitui outro obstáculo ao sucesso escolar dos alunos na escola em ciclos. O referido Programa, na representação dos docentes, contribui para que as famílias considerem a escola um depósito. Afirmaram:

[...] pra eles é só o Bolsa Família. Vou mandar pra escola por causa do Bolsa Família, não interessa o que ele faça, o que importa é está dentro da escola. [...] Tudo que estamos vivendo hoje é reflexo historicamente da desvalorização da educação e da família, tudo que você vê hoje... (P9)

[...] atualmente a gente perde muito tempo trabalhando a questão da indisciplina, porque eles vêm pra escola como se aqui fosse um depósito de crianças, as mães têm essa noção e joga mesmo. (P10)

Aí chama a família "venha participar", hoje tem plantão pedagógico, e vai ver quantos, dá pra contar nos dedos as mães que vem, porque pra eles a escola, a maioria, não todos [...]A maioria vê a escola como um depósito, "vou colocar, porque eu quero descansar". E tudo isso atrapalha o processo. Veja, se você... Nós quando éramos 
pequenas, nossa mãe não estabelecia uma rotina em casa? E não incentivava a gente a estudar? Eles não têm isso não! (P2)

Chechia e Andrade (2005), quando analisam o desempenho escolar na percepção dos pais de alunos de sucesso e fracasso escolar, pontuam que a presença dos pais nas atividades da escola contribui e favorece o sucesso. Mostram que a maioria dos pais de alunos com filhos em situação de insucesso escolar não tem esse envolvimento, carrega uma trajetória de frustrações em relação à escola e possui baixa escolaridade. Os autores dão destaque às famílias de alunos considerados "problemas" e indicam que esses pais sentem vontade de ajudar os filhos, contudo, não se sentem preparados.

O conteúdo da Classe 2 desvela por parte dos docentes investigados representações negativas das famílias dos seus alunos. O grupo ressaltou que a proposta de ciclos não ameniza nem supera as barreiras entre família e escola e acrescenta que, para o ciclo dar certo, essa interação é indispensável.

Os docentes alegam que a maior parte dos pais/familiares sequer pergunta ou procura acompanhar o desenvolvimento das aprendizagens, ao contrário, quando se aproxima dos professores é a fim de contabilizar as faltas dos estudantes, de modo a confirmar a garantia do acesso ao benefício do Programa Bolsa Família. Lembramos que Machado (2013), ao analisar as representações sociais de ciclos de gestores escolares, também constatou junto a esses profissionais que a inexistência de parceria da escola com as famílias é um aspecto que contribui para "minar o caráter promissor da proposta de ciclos".

O conteúdo da Classe 2 revela que as representações sociais dos professores estão ancoradas na relação escola/família com um dos elementos fundamentais para o sucesso ou insucesso dos alunos na escola organizada em ciclos. Identificou-se uma representação dessas famílias eivada de preconceitos e prejulgamentos. A representação social de família envolvida, parceira da escola e do professor no processo de ensino e aprendizagem orienta as práticas dos professores de sucesso nos ciclos de aprendizagem. Há uma expectativa por parte desses docentes que não tem sido correspondida pelos grupos com os quais lidam.

A Classe 3 - Fatores que promovem o sucesso escolar - é composta por 128 UCEs, referente a $15 \%$ do total analisado. Integram a referida classe as seguintes palavras: sucesso $(f=33)$; professor $(f=68)$; compromisso $(f=14)$; acredit (acredita, acreditando, acreditar, acredito) $(f=42)$; postura $(f=10)$; 
responsabilidade ( $f=11)$; valoriz (valorização, valorizar) $(f=9)$ e busc (busco, buscar) $(\mathrm{f}=19)$.

Conforme os termos presentes na terceira Classe, para os professores, apesar da imposição da proposta e dos desafios do trabalho docente na escola em ciclos, o sucesso é possível e decorre da postura, da responsabilidade e do compromisso que assumem como professores.

As palavras buscar e acreditar foram repetidas inúmeras vezes pela maioria dos entrevistados. Eles ressaltaram que, independentemente da proposta ou organização curricular da escola, procuram novos conhecimentos e acreditam que é possível desenvolver um bom trabalho. A esse respeito, Mendes (2008), em estudo sobre o professor de sucesso, mostra que o compromisso profissional faz superar as adversidades da escola e da sala de aula. Os depoimentos da Classe 3 retratam os professores bem-sucedidos, que falam de si próprios e dos recursos que mobilizam para garantir o sucesso de suas práticas. A título de ilustração eis o que afirmaram:

[...] acredito na mediação do professor... Acredito. Às vezes tudo é contra... Mas, você tem que acreditar... Planejo aos sábados... Não sei trabalhar sem planejar... Perco o fim de semana muitas vezes, porque eu acredito... Tem que acreditar... [...] Eu tento dar o meu melhor, dentro das minhas condições... (P5)

[...] estou sempre me esforçando para aprender mais, busco aprender sempre. Sou dedicada, acredito no meu trabalho, me esforço. [...] Faço minha parte, estou todo dia, não sou faltosa, não chego atrasada, sempre planejo, busco o novo... (P8)

[...] Sempre achei que professor é uma profissão que tem que estudar muito... É uma coisa que eu gosto muito. Quando quero fazer uma coisa estudo para fazer bem-feita e exijo muito de mim. (P10)

Conforme o conteúdo da Classe 3, as práticas de sucesso são possíveis porque os professores, individualmente ou com apoio da instituição escolar, buscam superar os desafios cotidianos de modo a garantir a aprendizagem dos alunos. O conjunto dos depoimentos corrobora o já dito por Naiff e Naiff (2013), quando enfatizam o papel dos professores para o bom funcionamento da proposta de ciclos.

A Classe 4 - Os ciclos na prática cotidiana - sinaliza a ancoragem das representações sociais da proposta de ciclos. O agrupamento é composto por 79 
UCEs, correspondendo a $9 \%$ do total geral do corpus. O conteúdo dessa classe desvela as práticas e o trabalho diário com os estudantes. As palavras nela reunidas foram: quadro ( $\mathrm{f}=14)$; aula $(\mathrm{f}=21)$; motiv (motivação, motivado, motivar, motivo) $(\mathrm{f}=6)$; exijo ( $\mathrm{f}=6)$; histor (história, histórias, historinhas) $(\mathrm{f}=10)$; atenção $(\mathrm{f}=4)$; amor $(\mathrm{f}=4)$; alegria $(\mathrm{f}=4)$ e prazer $(\mathrm{f}=5)$. Essas palavras estão relacionadas às estratégias que os professores utilizam para trabalhar enfrentando dificuldades das mais diferentes ordens na escola.

Algumas palavras agrupadas na quarta Classe revelam que os participantes fazem uso do que está disponível no cotidiano, não ficam presos às precárias condições vivenciadas no espaço escolar. Eles indicaram o quadro como um recurso que estimula a cooperação e o trabalho coletivo, um dos recursos mais utilizados para desenvolver atividades individuais ou em grupo. Para os docentes, ir ao quadro para responder a uma atividade constitui um rico momento de interação e construção coletiva de conhecimentos.

Referiram-se à utilização de outros recursos e estimuladores da aprendizagem, disseram que se empenham em motivar os alunos, fazê-los participar e demonstraram fazer de suas aulas momentos prazerosos e úteis à apropriação dos conteúdos trabalhados. Os docentes de sucesso se consideraram exigentes e defenderam que a proposta de ciclos de aprendizagem não os estimula a deixar de exigir bons resultados por parte de seus alunos. Por fim, defenderam a importância do trabalho em grupo e relação professor/aluno pautada na afetividade. Eis algumas das falas destes professores:

Eu tento trazer coisas novas, porque se eu não me sentir motivado eu não vou conseguir dar aula e nem as crianças vão se dedicar a aprender. Eu só consigo trabalhar assim. (P17)

Eu fiz um teste com eles (os alunos) usando os tablets distribuidos pela prefeitura, eles nem queria ir embora. Poxa! Eu me senti realizado, postei essa experiência nas redes sociais para que meus amigos e outros professores vissem. (P8)

Por exemplo, se vou trabalhar algo relacionado a aves, eu trago figuras daquele filme, Rio, porque faz sentido para eles e ai eles participam. (P4)

Muitos dos entrevistados trabalhavam com turmas de alfabetização, portanto, durante as entrevistas, se referiram ao desenvolvimento de práticas que valorizam o letramento, fizeram referências, principalmente, à contação de histórias, à construção coletiva de textos e a outras estratégias como memorização de palavras e sílabas. Afirmaram: 
Não sou tradicional, a gente tem que ser para o aluno aquilo que ele compreende melhor, aquilo que vai trazer para ele maior beneficio, se $o$ ba be bi bo bu para um aluno é o que traz mais resultado, então eu vou fazer o ba be bi bo bu, se para outro aluno é com textos amplos então para aquele vai ser isso. (P13)

Sou uma professora rigorosa e rígida, realmente eu sou e preciso ser, porque se eu não for desse jeito eles... Trabalho muito construindo conhecimento com eles. (P7)

[...] Trago comigo um plano B, então termina uma atividade eu jogo outra, terminou a outra eu já passo outra, tá entendendo, que é pra que eles se sintam tão ocupados a ponto de não dá tempo, não tenham permissividade deles fazerem outras coisas. (P16)

Enfim, na Classe 4, estão reunidos termos vinculados à prática docente nos ciclos e, conforme indicaram os depoimentos, os entrevistados reconhecem o aluno como um sujeito de saber e transitam entre tendências tradicionais e mais inovadoras de alfabetização.

\section{Considerações finais}

Os resultados sinalizaram uma representação social positiva e promissora dos ciclos de aprendizagem por parte dos professores considerados bem-sucedidos. As classes geradas pelo Alceste e, aqui discutidas, indicaram que os professores conhecem os elementos defendidos pela proposta (acompanhamento, registro e competência) e reconhecem que esses elementos são potencializadores do êxito escolar. Contudo, de acordo com os depoimentos, as condições de infraestrutura das escolas, a falta de acompanhamento por parte do sistema municipal, a ausência de apoio e de parceria das famílias, a desvalorização geral da educação e da profissão docente comprometem o sucesso dos ciclos de aprendizagem como proposta de correção de fluxo escolar. Esse conhecimento revela que o regime de ciclos tem sido, por vezes, objetivado de maneira contraditória pelos docentes. Um deles destacou: "o ciclo é bom, mas requer que outras dimensões estejam bem alinhadas".

Os elementos que caracterizam as práticas de sucesso dos professores estão interligados ao cotidiano e as representações sociais de ciclos de aprendizagem. Desse modo, pode-se concluir, afirmando que as representações sociais de ciclos de aprendizagem que orientam as práticas de professores bem-sucedidos na 
escola municipal são positivas e promissoras. No entanto, foram identificados os seguintes aspectos: insatisfação desses professores para com o modo de implementação da proposta; incoerência do modelo formativo de avaliação com as exigências do sistema; clareza em relação aos limites e dificuldades (materiais e de infraestrutura) no interior das escolas e descrença na possibilidade de construção de uma parceria com as famílias dos seus alunos. Tais elementos integram as representações sociais de ciclos do grupo pesquisado.

Mesmo tendo identificado representações sociais positivas para com o sistema de ciclos de aprendizagem entre os professores de sucesso, notou-se que o sistema de seriação ainda tem um grande espaço na forma como esses profissionais conduzem suas práticas, sobretudo, no plano avaliativo. Alguns professores revelaram grande preocupação com o mundo do trabalho, seletividade e exigências das avaliações institucionais. É importante ressaltar, como afirma Sousa (2007), que a proposta de ciclos requer um novo olhar para os objetivos e fins da educação, só assim essa proposta poderá subsidiar a construção de uma escola de qualidade para todos e de uma cultura avaliativa menos seletiva e excludente.

Semelhante a outras pesquisas sobre os ciclos, os professores de sucesso, ouvidos nesta pesquisa, reiteraram que a falta de suporte técnico, ausência de formação continuada e tempo para estudo, precárias condições de trabalho nas escolas, falta de apoio e parceria das famílias são entraves que dificultam o avanço efetivo da proposta.

Os resultados deixaram entrever, ainda, que os professores de sucesso, devido ao compromisso e responsabilidade com que encaram a docência, possuem representações sociais positivas quanto ao potencial transformador da escola. Para eles, independentemente do seu modo de organização, essa capacidade que a escola/educação possui de mudar o destino das pessoas orienta suas práticas bem-sucedidas, no contexto da escola pública.

A investigação realizada traz contribuições para o campo das políticas educacionais, pois, quando desvela a dimensão simbólica de ciclos de aprendizagem, que está articulada às práticas bem-sucedidas, sinaliza para a necessidade do redimensionamento das políticas de correção de fluxo escolar. Tais políticas têm garantido a permanência do estudante na escola, porém não têm sido eficientes para assegurar sua efetiva aprendizagem. 


\title{
Schools organized in cycles: the social representations considered successful by teachers
}

\begin{abstract}
This article identifies the social representations of successful learning cycles as considered by teachers, drawing upon Serge Moscovici's theory of social representations. Participants included 20 teachers from the municipality of Recife in Brazil. In depth interviews were conducted, which were then processed using Alceste software to prepare reports. The corpus was arranged into the following four categories: knowledge relating to the proposed cycles; the proposal's challenges and drawbacks; factors promoting school success; and cycles in everyday practice. Overall, these categories reveal that teachers are familiar with the system cycles and underscore the limits and impediments that interfere with their effectiveness. Results indicated that successful teachers, characterized by responsibility and commitment to teaching, display positive social representations with respect to the school's transformative potential, regardless of their organizational processes. Furthermore, these representations guide their practices in schools organized in cycles.
\end{abstract}

Keywords: Social representations. Successful practices. Learning cycles.

\section{Escuela organizada en ciclos: las representaciones sociales de maestros considerados exitosos}

\section{Resumen}

El artículo identifica las representaciones sociales de ciclos de aprendizaje de maestros considerados exitosos Teniendo como referencia la Teoría de las Representaciones Sociales en la vertiente original de S. Moscovici. La investigación se realizó con 20 maestros de la Red Municipal de Recife- PE. Los profesionales respondieron una encuesta realizada en profundidad. Las declaraciones fueron procesadas usando el software Alceste. El corpus fue organizado en cuatro clases llamadas: conocimientos relacionados con las propuestas de ciclos; problemas y deficiencias de la propuesta; factores que promueven el éxito escolar y los ciclos en la práctica cotidiana. En general, las clases revelan que los maestros conocen los ciclos del sistema destacando los límites y dificultades que interfieren con su eficacia. Los resultados dejaron en evidencia que los docentes exitosos, debido al compromiso y la responsabilidad con respecto a la enseñanza, tienen representaciones sociales positivas sobre el potencial transformador de la escuela, independientemente de sus procesos organizativos y son estas representaciones que orientan sus prácticas en la escuela organizada por ciclos.

Palabras clave: Representaciones sociales. Prácticas exitosas. Aprender ciclos. 


\section{Referências}

ANDRADE, C.; RAITZ, T. R. As possíveis razões do sucesso escolar em duas escolas públicas. Seminário de pesquisa e educação da região sul. In: ANPED Sul, 9., Caxias do Sul, 2012. Anais... Caxias do Sul: Universidade de Caxias do Sul,. 2012. p. 1-15.

BONA, J.; SILVA, N. M. A. Cultura e práticas escolares: um olhar a partir das representações sociais. Revista Espaço Pedagógico, Passo Fundo, v. 16, n. 2 , p. 7-19, jul. /dez. 2009.

BRASIL. Lei $\mathrm{n}^{\circ}$ 9.394, de 20 de dezembro de 1996. Estabelece as diretrizes e bases da educação nacional. Diário Oficial da União, 23 dez. 1996.

BUENO, B. O.; GARCIA, T. F. Êxito escolar: as regras da interação na sala de aula. Revista Brasileira de Estudos Pedagógicos, Brasília, v. 77, n. 186, p. 263-81, maio/ago. 1996.

CAMARGO B. V. Alceste: um programa informático de análise quantitativa de dados textuais. In: MOREIRA, A. S. P. (Org.). Perspectivas teórico-metodológicas em representações sociais. João Pessoa: UFPB/Ed Universitária, 2005. p. 511-39.

CHECHIA, V. A.; ANDRADE, A. S. O desempenho escolar dos filhos na percepção de pais de alunos com sucesso e insucesso escolar. Estudos de Psicologia, Natal, v. 10, n. 3, p.431-40, set./dez. 2005. doi:10.1590/S1413-294X200500030001

DUARTE, J. Entrevista em profundidade. In: BARROS, A.; DUARTE, J. (Orgs.). Método e técnicas de pesquisa em comunicação. São Paulo: Atlas, 2005. p. 206-18.

ESTEBAN, M. T. (Org.). Escola, currículo e avaliação. São Paulo: Cortez, 2003. (Série Cultura, memória e currículo, 5).

JACOMINI, M. A. Os educadores e a organização do ensino em ciclos na rede municipal de São Paulo (1992-2001). Revista Factus, São Paulo, v. 3, p. 95-112, jan./abr. 2007.

LIMA, R. C. P.; FERNANDES, M. C. S. G. Representações sociais de alunas de pedagogia sobre suas trajetórias escolares. Educação Unisinos, São Leopoldo, v. 12, n. 3, p. 215-25, set./dez. 2008. 
MACHADO, L. B. Eles "passam de bolo" e ficam cada vez mais analfabetos: discutindo as representações de ciclos de aprendizagem entre professores. Psicologia da Educação, São Paulo, n. 24, p. 111-28, jun. 2007.

. Gestores escolares e suas representações sociais de ciclos de aprendizagem. Revista Espaço Pedagógico, Passo Fundo, v. 20, n. 2, p. 321-33, jul./dez. 2013.

MACHADO, L. B.; ANICETO, R. A. Núcleo central e periferia das representações de ciclos de aprendizagem entre professores. Ensaio: Avaliação e Políticas Públicas em Educação, Rio de Janeiro, v. 18, n. 67, p. 345-64, abr.jun. 2010. doi:10.1590/S0104-40362010000200009

MACHADO, L. B.; AZEVEDO, M. F.; FREIRE, S. B. O "bom" professor universitário nas representações sociais de estudantes de pedagogia. Roteiro, Joaçaba, v. 38, n. 2, p. 311-36, jul./dez. 2013.

MARIANO, A. L. S.; DINIZ, J. A. R.; TANCREDI, R. M. S. P. O início da docência de uma professora considerada bem-sucedida: apontamentos a partir de relatos orais. Olhar de Professor, Ponta Grossa, v. 10, n. 2, p.47-58, 2007.

MAINARDES, J. Escola em ciclos: fundamentos e debates. São Paulo: Cortez, 2009.

MENDES, M. C. J. Professoras bem-sucedidas: saberes e práticas significativas. In: Constituição Brasileira, Direitos Humanos e Educação. REUNIÃO NACIONAL DA ANPED, 31., 2008, Caxambu. Rio de Janeiro: Anped, 2008.

MIRANDA, M. G. Sobre tempos e espaços da escola: do princípio do conhecimento ao princípio da socialidade. Educação \& Sociedade, Campinas, v. 26, n. 91, p. 639-51, maio/ago. 2005. doi:10.1590/S0101-73302005000200017

MONTEIRO, M. I. M. I. Histórias de vida de professoras bem-sucedidas como fundamento de organização de políticas educativas de formação de alfabetizadores. In: Necessidades emergentes da sociedade do conhecimento para a formação do educador: mitos e desafios, CONGRESSO INTERNACIONAL EM EDUCAÇÃO ESCOLAR, 1., 2011, Araraquara., 2011. Anais... Araraquara: UNESP, 2011. p. 1-9.

MOSCOVICI, S. A representação social da psicanálise. Rio de Janeiro: Jorge Zahar, 1978. 
MOSCOVICI, S. Representações sociais: investigações em psicologia social. 5. ed. Petrópolis: Vozes, 2007.

NAIFF, L. A. M.; NAIFF, D. G. M. Organização da escolaridade em ciclos: representações sociais de professores. Psicologia \& Sociedade, Belo Horizonte, v. 25, n. 3, p. 538-48, 2013. doi:10.1590/S0102-71822013000300008

PERRENOUD, P. Avaliação: da excelência à regulação das aprendizagens: entre duas lógicas. Porto Alegre: Artmed, 1999.

PETRENAS, R. C.; LIMA, R. C. Ciclos de aprendizagem e reprovação escolar: reflexões sobre representações sociais de professores. Revista Práxis Educativa, Ponta Grossa, v. 2, n. 2, p. 161-8, jul. 2007.

POMBO DE BARROS, C. F. Análise textual com o programa Alceste: uma aplicação em pesquisas de representações sociais no campo da política. In: MATTOS, R. A.; BAPTISTA, T. W. F. Caminhos para análise das políticas de saúde. Rio de Janeiro, 2011. p. 275-8.

RECIFE. Prefeitura Municipal. Secretaria Municipal de Educação. Proposta pedagógica da rede ao municipal de ensino do Recife: construindo competências. Recife, 2003.

. Prefeitura Municipal. Secretaria Municipal de Educação. Tempos de aprendizagem, identidade cidadã e organização da educação escolar em ciclos. Recife, 2002.

RIOS, T. A. Compreender e ensinar: por uma docência de melhor qualidade. São Paulo: Cortez, 2002.

SÁ, C. P. A construção do objeto de pesquisa em representações sociais. Rio de Janeiro: EdUERJ, 1998.

SOUSA, S. Z. Avaliação, ciclos e qualidade do ensino fundamental: uma relação a ser construída. Estudos Avançados, São Paulo, v. 21, n. 60, p. 27-44, maio/ago. 2007. doi:10.1590/S0103-40142007000200003 


\section{Informações dos autores}

Laêda Bezerra Machado: Doutorado em Educação. Professora Associada, vinculada ao Departamento de Administração Escolar e Planejamento Educacional e Programa de Pós-graduação em Educação - Núcleo de Formação de Professores e Prática Pedagógica da Universidade Federal de Pernambuco - UFPE. Recife, Pernambuco, Brasil; Bolsista de produtividade em Pesquisa do CNPq. Contato: laeda01@gmail.com

Jaqueline Andréa Lira Cordeiro Santos: Estudante de Graduação de Pedagogia da Universidade Federal de Pernambuco - UFPE. Bolsista de Iniciação Científica - PIBIC/CNPq. Contato: jaquelineliragomes@hotmail.com 